\title{
Martensitic Transformation in Nanostructured NiTi Alloy Studied by X-ray Diffraction In-Situ Heating
}

\author{
Paweł Świec ${ }^{1}$, Maciej Zubko ${ }^{1,2, *}$, Danuta Stróż ${ }^{1}$ and Zdzisław Lekston ${ }^{1}$ \\ ${ }^{1}$ Institute of Materials Science, University of Silesia, Chorzów, Poland \\ ${ }^{2}$ Department of Physics, University of Hradec Králové, Hradec Králové, Czech Republic
}

In this work martensitic transformation of Ni-rich NiTi alloy subjected to 17, 20 and $35 \%$ cold-rolling in the martensitic state followed by annealing at $450^{\circ} \mathrm{C}$ for $15 \mathrm{~min}$ has been studied by in-situ X-ray Diffraction, Transmission Electron Microscopy and Differential Scanning Calorimetry. It has been found that the material after thermo-mechanical treatment has ultra-fine grained structure with small number of large grains with high dislocation density. Phase composition of that nanostructured alloy consists of B2 austenite, B19' martensite and R rhombohedral phases. B2 and B19' were stable at high as well as at low temperatures. DSC measurements revealed that the studied material shows multistage character of phase transformation. Therefore it was decided to adopt in-situ XRD analysis. [doi: $10.2320 /$ matertrans.MC201808]

(Received October 12, 2018; Accepted January 17, 2019; Published April 25, 2019)

Keywords: nanostructured materials, nickel titanium shape memory alloy, severe cold-rolling, in-situ X-ray diffraction, martensitic transformation

\section{Introduction}

Near equi-atomic NiTi alloys exhibit the phenomenon of shape memory and superelasticity. These two unusual effects are due to thermally or stress induced thermoelastic reversible martensitic transformation. This first order solid to solid phase transition proceeds between high temperature austenite phase B2 and low temperature martensite phase B19'. ${ }^{1)}$ After deformation in martensite state material during heating undergoes reversible transformation and recovers its original shape. This makes it a very useful material in industry and medicine. Characteristic temperatures can be adjusted by variation of chemical composition of the alloy ${ }^{2)}$ as well as applying mechanical ${ }^{3,4)}$ and thermal treatment. ${ }^{5)}$ After such treatments an intermediate $\mathrm{R}$ phase will precede the martensitic transformation. Presence of that phase is caused by crystal lattice strain e.g. by high dislocation density, semicoherent $\mathrm{Ni}_{4} \mathrm{Ti}_{3}$ precipitates or grain size reduction. ${ }^{6}$ )

Koike et $a{ }^{7}{ }^{7)}$ showed that NiTi alloys are susceptible to amorphization which gives a possibility for the production of bulk nanocrystalline form of that material. The amorphization can be obtained by severe plastic deformation (SPD). Nanocrystalline materials have enhanced mechanical properties like yield strength or hardness. Also chemical properties e.g. corrosion resistance and osteointegration can be improved. ${ }^{8-10)}$ These unique properties are highly appreciated in the case of materials used in bone anastomosis. NiTi alloys after SPD and post deformation annealing have relatively high yield strength, but also different character of the martensitic transformation. In grains smaller than $50 \mathrm{~nm}$ thermally induced transformation is suppressed. This is related to austenite/martensite interface thickness in the nanostructured alloy which is thicker than the grain diameter. However, this transformation may be still induced by applying external stress. This makes utilization of the superelastic effect possible in a very wide temperature range. ${ }^{11,12)}$

*Corresponding author, E-mail: maciej.zubko@us.edu.pl
Previous studies showed that nanostructured NiTi alloy can be also obtained by cold rolling at martensitic state. ${ }^{13,14)}$ Deformation at low temperatures prevents the processed material form dynamic recovery, dynamic recrystallization and in this case unfavorable superelastic effect. ${ }^{15)} \mathrm{NiTi}$ alloys formed by severe cold rolling exhibit different character of transformation than alloys processed by high pressure torsion or equal channel angular pressing. ${ }^{13)}$ Between the $\mathrm{B} 2 \rightarrow \mathrm{R}$ and $\mathrm{R} \rightarrow \mathrm{B} 19^{\prime}$ transformations still additional transformation starts to occur. In the DSC studies for cold rolled NiTi alloy aged at different temperatures with different cooling rate, it was concluded that these additional heat effects might correspond to $\mathrm{B} 2 \rightarrow \mathrm{R}$ and also direct transformation $\mathrm{B} 2 \rightarrow$ B19'. ${ }^{16)}$ However, DSC studies consist only in measuring transformation heat. Therefore it is very useful to study structure changes during transformation for various deformation degrees. Thus, the purpose of this work was to apply in situ temperature X-ray diffraction studies of the transformations occurring in the nanostructured NiTi alloy.

\section{Experimental Procedure}

In present studies $\mathrm{Ni}_{50.7} \mathrm{Ti}_{49.3}$ alloy in a shape of $3.5 \mathrm{~mm}$ wire was used. The initial material is characterised mainly by coarse grains of the B2 phase. The martensite start temperature $\mathrm{Ms}$ is $14^{\circ} \mathrm{C}$ and the reverse $\mathrm{As}$ is $34^{\circ} \mathrm{C}$. The studied alloy was subjected to severe plastic deformation by cold rolling. Cold work was performed below martensite finish temperature $\mathrm{Mf}$ in order to suppress dynamic recrystallization, dynamic recovery and superelastic effect. ${ }^{15)}$ To maintain the material at that low temperature, it was cooled before each pass in liquid nitrogen. After achieving a 17,20 and $35 \%$ reduction in cross-sectional area, the alloy was heat-treated at $450^{\circ} \mathrm{C}$ for $15 \mathrm{~min}$.

During specimen preparation much effort was made to keep the material at room temperature. Samples were cut on water cooled precision saw and grinded with abrasive to final gradation of P2000. To study martensitic transformation differential scanning calorimetry (DSC) measurements were 
performed using a Mettler Toledo DSC- 1 with $10^{\circ} \mathrm{C} \cdot \mathrm{min}^{-1}$ heating/cooling rate. Also in-situ temperature X-ray diffraction measurements were performed using Malvern Panalytical Empyrean diffractometer equipped with PIXcell ${ }^{3 \mathrm{D}}$ detector and Anton Paar TTK 450 Low Temperature Chamber. During the XRD measurements the temperature was changed in $-120-100^{\circ} \mathrm{C}$ range with $10^{\circ} \mathrm{C}$ step. Transmission electron microscope (TEM) observations were performed using JEOL JEM 3010 with $300 \mathrm{kV}$ accelerating voltage equipped with $2 \mathrm{k} \times 2 \mathrm{k}$ OriusTM 833 SC200D Gatan CCD. TEM thin films were prepared by "twin-jet" electropolishing method using $20 \% \mathrm{H}_{2} \mathrm{SO}_{4}$ in methanol electrolyte with polishing voltage of $9 \mathrm{~V}$. CrystBOX software was used to index TEM diffraction images. ${ }^{17)}$

\section{Results}

Figure 1 presents the structure of cold rolled and annealed material (CR). All samples are characterized by ultra-fine grain structure and the grain size tends to become smaller with higher deformation degree. Selected area electron diffraction (SAED) patterns revealed that $17 \%$-CR and $20 \%$-CR structures are a mixture of B2, B19' and R phases forming lath structure which can be observed on dark field

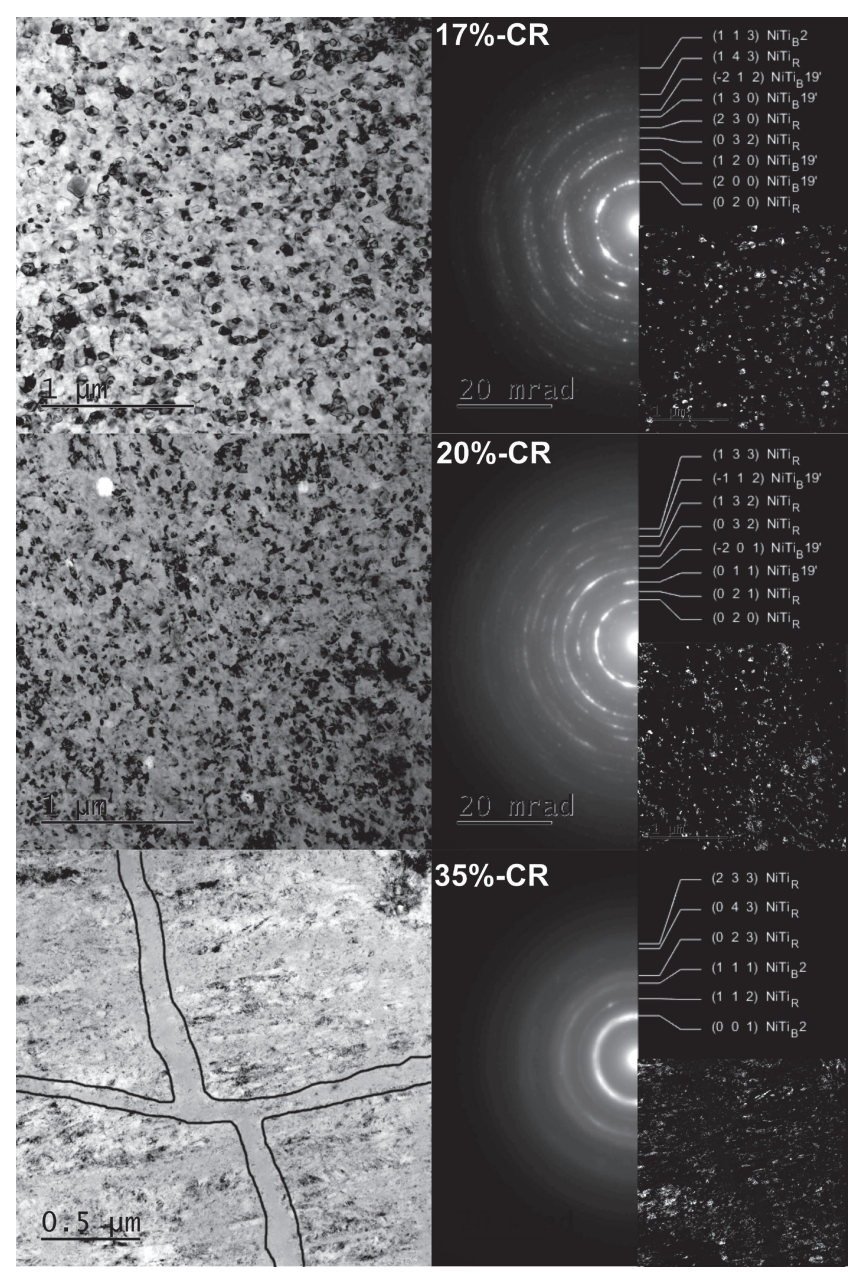

Fig. 1 Nanostructure of $17 \%-C R, 20 \%-C R$ and $35 \%-C R$ samples with indexed SAED patterns and DF images. images (DF) with grain size $83 \mathrm{~nm}$ and $62 \mathrm{~nm}$, respectively. It was also seen that samples had few areas with bigger grains and high dislocation density. In 35\% CR specimen the B19' phase was not observed but it contains a lot of canal-like shaped amorphous areas and the crystalline part was strongly defected. Grain size of that sample was estimated to be $32 \mathrm{~nm}$.

The DSC curves (Fig. 2) reveal multi-step character of the martensitic transformation. The peaks spread with increasing deformation degree and their enthalpy is getting lower. Peaks marked as 2 and 5 are clearly decreasing faster than the other peaks. Details of the DSC data are listed in Table 1.

In-situ temperature XRD analysis was performed to analyze temperature dependence of phases (Fig. 3). Diffraction patterns reveal that for $17 \%$-CR some part of the $\mathrm{R}$ phase does not undergo martensitic transformation. In $20 \%-$ $\mathrm{CR}$ also small amount of martensite and austenite do not transform neither on cooling nor on heating. This is clearly visible in diffraction patterns presented in Fig. 3(b) where retained martensite is indicated by arrows. On the contrary, in $35 \%$-CR specimen only small amount of the material undergoes transformations. To examine the temperature dependence between these phases the quantitative analysis needs to be performed. Standard quantitative analysis of martensitic transformation in nanostructured NiTi alloy are very complicated and uncertain due to existence of 3 main phases which diffraction peaks lie very close, existence of amorphous fractions as well as large peak broadening caused by internal stresses and small crystalline size. Because of

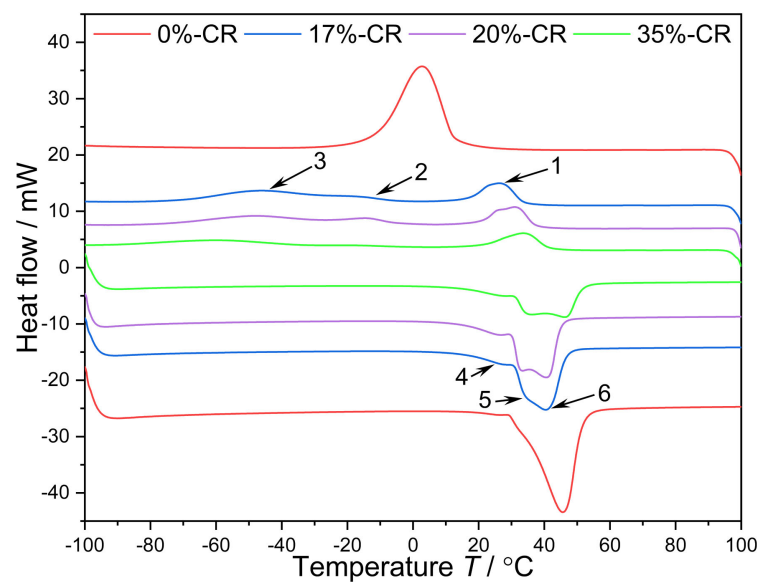

Fig. 2 DSC curves of $0 \%-C R, 17 \%-C R, 20 \%$-CR and $35 \%-C R$ samples revealing multistage character of transformation and changes at its characteristic temperatures.

Table $1 \mathrm{~T}_{\text {peak }}\left({ }^{\circ} \mathrm{C}\right)$ of DSC curves peaks of studied alloy.

\begin{tabular}{ccccccc}
\hline \multicolumn{3}{c}{ Cooling } & \multicolumn{3}{c}{ Heating } \\
\hline Peak & 1 & 2 & 3 & 4 & 5 & 6 \\
No. & & & & & & 40.5 \\
\hline $17 \%$-CR & 26.4 & -16.3 & -46.6 & 28.3 & 34.8 & 40.7 \\
\hline $20 \%$-CR & 30.9 & -15.2 & -47.8 & 26.2 & 33.0 & 40.7 \\
\hline $35 \%$-CR & 33.3 & -16.6 & 60.2 & 27.8 & 35.5 & 46.3 \\
\hline $0 \%-C R$ & & 2.20 & & & 46.32 & \\
\hline
\end{tabular}



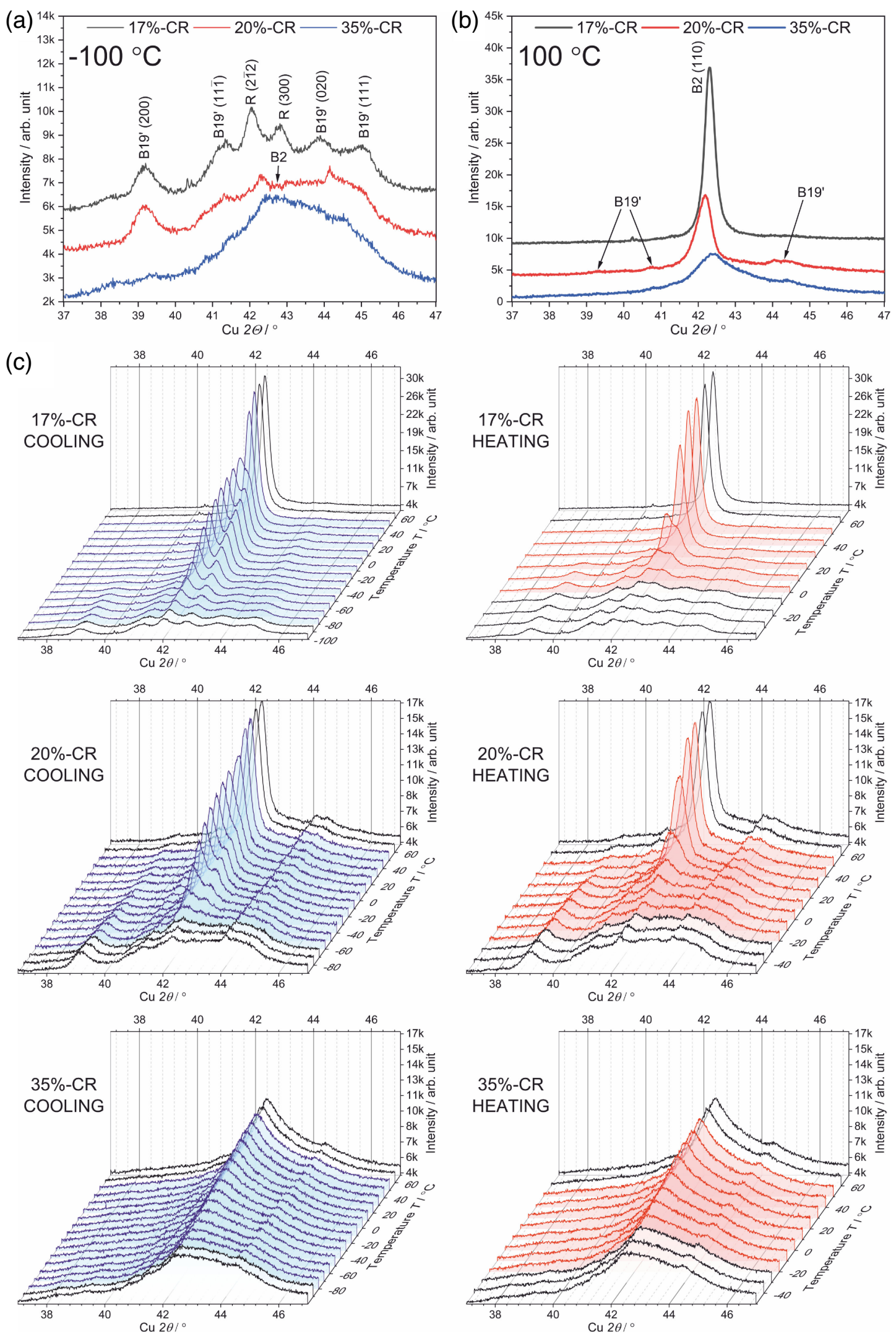

Fig. 3 XRD patterns of $17 \%$-CR, $20 \%$-CR and $35 \%$-CR at (a) $-100^{\circ} \mathrm{C}$ and (b) $100^{\circ} \mathrm{C}$ showing martensite and austenite stabilisation with (c) in-situ heating XRD patterns showing structure changes during martensitic transformation.

these problems non-standard analysis was adopted, the details of which are given in appendices.

According to this analysis we can conclude that in temperature range referring to DSC peak no. 1 during cooling the B2 phase content is getting lower in favour of the $\mathrm{R}$ phase (Fig. 4). During cooling in temperature range of the $3^{\text {rd }}$ DSC peak phase transformation occurs via $R$ phase to B19' martensite phase. Intensity of the B2 (110) peak is still 

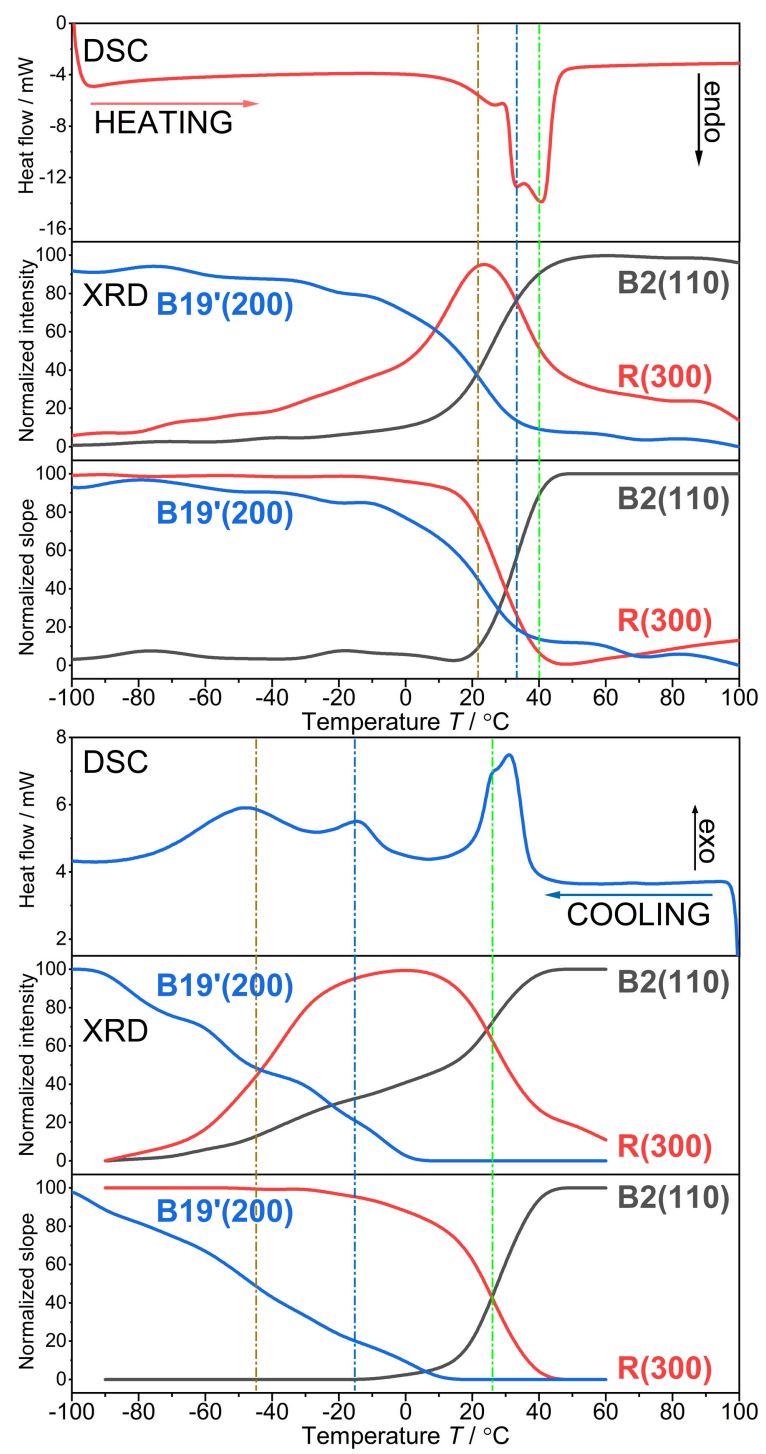

Fig. 4 Analysis of 20\%-CR sample in-situ XRD patterns performed by the method described in the appendix.

getting lower at temperature range of $2^{\text {nd }}$ DSC peak while the B19' phase starts to grow. It should be also denoted that the $\mathrm{B} 2$ peak intensity is decreasing faster than the $\mathrm{R}$ phase peak intensity. During the heating cycle the $\mathrm{R}$ phase peak intensity is increasing on expense of $\mathrm{B}^{\prime} 9^{\prime}$ decrease until reaching $\mathrm{T}_{\text {peak }}$ of the $4^{\text {th }}$ DSC peak.

Partial DSC curves were also recorded to determine correspondence between the observed thermal peaks (Fig. 5(a)). Studies have been carried out by heating sample up to $100^{\circ} \mathrm{C}$, partially cooling to specific temperatures between peaks and heating again for the reverse transformation to occur. This experiment allowed us to detect that peak no. 1 on cooling and peak no. 5 on heating correspond to the same transformation and have very narrow thermal hysteresis which is characteristic for $\mathrm{B} 2 \leftrightarrow \mathrm{R}$ phase transformation. Peak no. 3 refers to peak no. 4. Their characteristic temperatures are lower than the preceding pair and they have wide hysteresis. Thus, we concluded that they might correspond to $\mathrm{R} \leftrightarrow \mathrm{B} 19^{\prime}$ phase transformation. Last heat effects are related to the pair of peaks no. 2 and 6 with a very similar hysteresis to the $3 \leftrightarrow 4$ transformation but
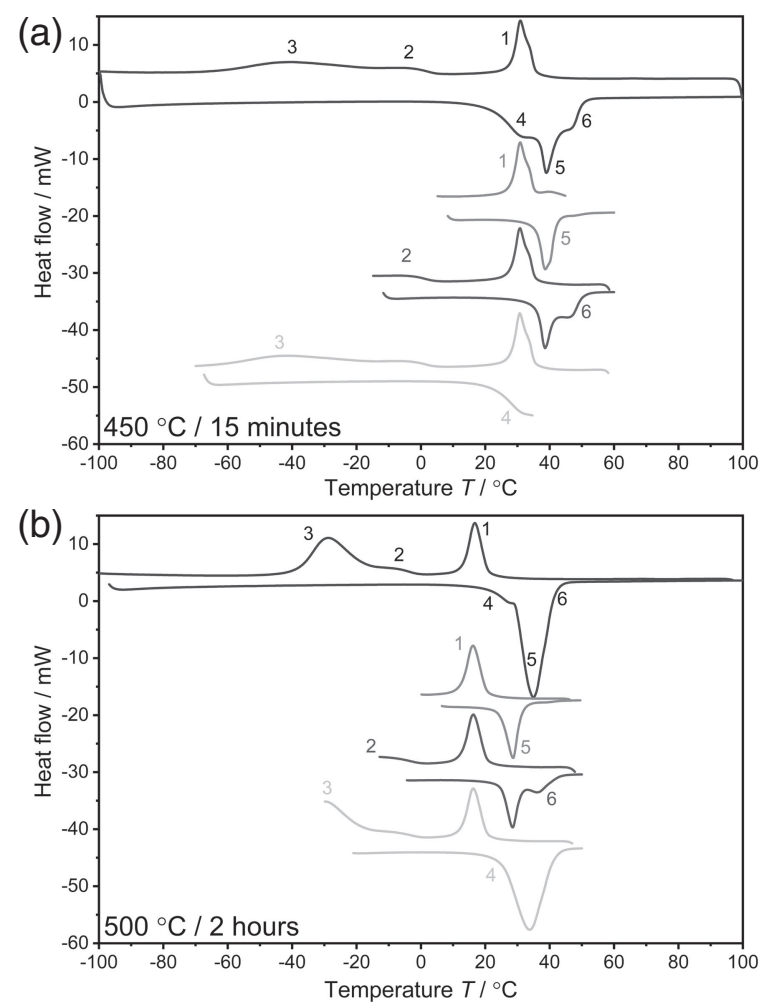

Fig. 5 Partial DSC of $35 \%$-CR annealed (a) at $450^{\circ} \mathrm{C}$ for 15 minutes and (b) at $500^{\circ} \mathrm{C}$ for 120 minutes, showing correspondence of peaks and changes in martensitic transformation after annealing in higher temperatures.

shifted to higher temperatures. In order to see how the martensitic transformation behaves in well crystallized material additional partial DSC curves (Fig. 5(b)) for the material after annealing at $500^{\circ} \mathrm{C}$ for 2 hours were obtained. These additional curves revealed that the transformations corresponding to peaks $1 \leftrightarrow 5$ and $3 \leftrightarrow 4$ are preferred because its enthalpy increased nearly 2 times whereas the transformation $2 \leftrightarrow 6$ hardly changed.

\section{Discussion}

The material after severe cold rolling in martensitic state have ultra-fine grain structure after $17 \% \mathrm{CR}$ and further annealing. TEM images revealed a small amount of areas with bigger grains and very high dislocation density. Those grains did not undergo recrystallization process. In the $35 \%$-CR sample amorphous areas were present. These areas are consequence of deformation mechanism and might be formed by amorphisation of secondary deformation band ${ }^{18)}$ or by dislocation stacking at initial grain boundaries. ${ }^{13,14)}$ All samples have multiphase structure of B2, R and B19' phases. With higher deformation degree it is clearly visible that some amount of the B19' martensite as well as the B2 austenite becomes stable at all temperatures. Stabilisation of the martensite is very common for plastically deformed NiTi alloys. ${ }^{19)}$ Stabilisation of high-temperature B2 phase is related with nanostructure having grains smaller than $50 \mathrm{~nm}$ which heat activated martensitic transformation does not occur. ${ }^{20)}$ Sun and Aslan et $a l^{21)}$ concluded that it depends on the 
thickness of the B2/B19' interface which is smaller than the grain diameter in ultra-fine grained structures.

Martensitic transformation occurring in the studied alloy have uncommon character. The DSC curves revealed 3 heat effects during cooling and heating. In-situ temperature XRD measurements showed that that transformation between $1^{\text {st }}$ and $5^{\text {th }}$ peaks correspond to $\mathrm{B} 2 \leftrightarrow \mathrm{R}$ phase transition which is also confirmed by a small thermal hysteresis of the transformation. DSC data listed in Table 1 also show that the higher degree of deformation, the higher temperature of the $\mathrm{R}$-phase transformation. This is consistent with the literature data $^{5)}$ that showing the lattice stress/strain favour the $\mathrm{R}$ phase transformation, while the B19' transformation is shifted to lower temperature. The differences in transformation temperatures given by XRD and DSC measurements are due to speed of cooling and heating used in the both methods.

The $3^{\text {rd }}$ and $4^{\text {th }}$ peaks correspond to $\mathrm{R} \leftrightarrow \mathrm{B} 19^{\prime}$ transformation. The last pair of peaks stays unclear and requires further discussion. Multistage phase transformation is very often caused by $\mathrm{Ni}_{4} \mathrm{Ti}_{3}$ precipitates, which make the matrix to be depleted in nickel and cause transformation to occur at different temperatures near the precipitates and at different temperatures in areas distant from them. ${ }^{22)}$ These precipitates might be formed at $450^{\circ} \mathrm{C}$ but they have not been observed during TEM studies. Plastic deformation induce the $\mathrm{R}$ phase transformation due to high residual strains accumulated in the material. Inhomogeneity in the stress field caused by changes in the dislocation configuration during the recovery process results in two different paths of phase transformation. ${ }^{23)}$ However, if peak 2 corresponds to $\mathrm{R} \rightarrow \mathrm{B} 19^{\prime}$ transformation,

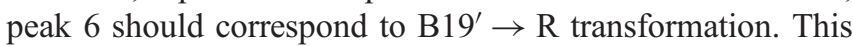
mechanism is very unlikely since peak 6 forms after peak 5 (corresponding to $\mathrm{R} \rightarrow \mathrm{B} 2$ ). Adharapurapu and Vecchio came to similar conclusions in their work. ${ }^{16)}$ Additionally XRD analysis did not show any amount difference of the $\mathrm{R}$ phase in peak 6 temperature range during heating but it showed small decrease of B2 phase peak in favour of B19' at temperature range corresponding to $2^{\text {nd }}$ DSC peak. This indicates the occurrence of the direct B2 $\leftrightarrow$ B19' martensitic transformation. That patch of transformation is not prohibited since there is no thermomechanical restrictions to the combinations of $\mathrm{B} 2 \leftrightarrow \mathrm{B} 19^{\prime}$ and $\mathrm{B} 2 \leftrightarrow \mathrm{R} \leftrightarrow \mathrm{B} 19^{\prime}$ transformations. ${ }^{24,25)}$ Partial DSC data for the sample annealed at $500^{\circ} \mathrm{C}$ for $2 \mathrm{~h}$ showed that enthalpy of that transformation is not changed by higher temperature or longer time of heat treatment. Additionally it is visible that the reverse transformation occurs in one peak and it is positioned on the highest temperature range of all heating DSC peaks. These facts lead to the conclusion that these DSC thermal effects correspond to the direct transformation of B2 $\leftrightarrow$ B19' which might be result of the material structure inhomogeneity. However, more detailed research must be done e.g. in-situ TEM observations or synchrotron radiation studies in order to confirm these assumptions.

\section{Conclusion}

NiTi alloy subjected to 17,20 and $35 \%$ deformation and annealing at $450^{\circ} \mathrm{C}$ for 15 minutes results in obtaining nanostructured form of the material. Structure of the material was not fully homogenous. It contained few areas of large grains with very high dislocation density. It has been shown that with higher deformation degree some parts of B19' martensite as well as B2 austenite phases are stable at high and low temperatures, respectively. This is caused by presence of residual strains and grains smaller than $50 \mathrm{~nm}$ at which the martensitic transformation does not occur. The studied material have multistage character of the martensitic transformation. In-situ XRD and partial DSC studies revealed the $\mathrm{B} 2 \leftrightarrow \mathrm{R} \leftrightarrow \mathrm{B} 19^{\prime}$ path of transformation. It was concluded that material might also undergo direct transformation B2 $\leftrightarrow$ B19'.

\section{REFERENCES}

1) K. Otsuka and X. Ren: Prog. Mater. Sci. 50 (2005) 511-678.

2) J. Frenzel, E.P. George, A. Dlouhy, C. Somsen, M.F.X. Wagner and G. Eggeler: Acta Mater. 58 (2010) 3444-3458.

3) H. Morawiec, J. Ilczuk, D. Stróz, T. Goryczka and D. Chrobak: J. Phys. IV 07 (1997) C5-155-C5-159.

4) H. Morawiec, D. Stróz and D. Chrobak: J. Phys. IV 05 (1995) C2-205C2-210.

5) D. Chrobak and D. Stróz: Scr. Mater. 52 (2005) 757-760.

6) X.B. Wang, B. Verlinden and J. Van Humbeeck: Mater. Sci. Technol. 30 (2014) 1517-1529.

7) J. Koike, D.M. Parkin and M. Nastasi: J. Mater. Res. 5 (1990) 14141418.

8) M.A. Meyers, A. Mishra and D.J. Benson: Prog. Mater. Sci. 51 (2006) 427-556.

9) R.Z. Valiev, I.P. Semenova, V.V. Latysh, H. Rack, T.C. Lowe, J. Petruzelka, L. Dluhos, D. Hrusak and J. Sochova: Adv. Eng. Mater. 10 (2008) B15-B17.

10) R. Valiev, D. Gunderov, E. Prokofiev, V. Pushin and Y. Zhu: Mater. Trans. 49 (2008) 97-101.

11) A. Ahadi and Q. Sun: Appl. Phys. Lett. 103 (2013) 021902.

12) T. Waitz, T. Antretter, F.D. Fischer and H.P. Karnthaler: Mater. Sci. Technol. 24 (2008) 934-940.

13) P. Świec, M. Zubko, D. Stróż and Z. Lekston: Int. J. Mater. Res. 109 (2018) 1-6.

14) P. Świec, M. Zubko, Z. Lekston and D. Stróż: Acta Phys. Pol. A 131 (2017) 1307-1311.

15) S. Jiang, L. Hu, Y. Zhao, Y. Zhang and Y. Liang: Mater. Sci. Eng. A 569 (2013) 117-123.

16) R.R. Adharapurapu and K.S. Vecchio: J. Alloys Compd. 693 (2017) 150-163.

17) M. Klinger: J. Appl. Cryst. 50 (2017) 1226-1234.

18) S. Jiang, L. Hu, Y. Zhang and Y. Liang: J. Non-Cryst. Solids 367 (2013) 23-29.

19) A.S. Paula, J.H.P.G. Canejo, K.K. Mahesh, R.J.C. Silva, F.M.B. Fernandes, R.M.S. Martins, A.M.A. Cardoso and N. Schell: Nucl. Instruments Methods Phys. Res. Sect. B 246 (2006) 206-210.

20) T. Waitz, V. Kazykhanov and H.P. Karnthaler: Acta Mater. 52 (2004) 137-147.

21) Q. Sun, A. Aslan, M. Li and M. Chen: Sci. China Technol. Sci. 57 (2014) 671-679.

22) D. Stróż and D. Chrobak: Mater. Trans. 52 (2011) 358-363.

23) H. Morawiec, D. Strószlig, T. Goryczka and D. Chrobak: Scr. Mater. 35 (1996) 485-490.

24) Y. Liu and P.G. McCormick: Mater. Trans., JIM 37 (1996) 691-696.

25) Y. Liu, H. Yang and A. Voigt: Mater. Sci. Eng. A 360 (2003) 350-355.

\section{Appendix}

Linear function was fitted into the diffraction pattern in range between $\mathrm{B} 2(110)$ peak which position is $42.23^{\circ} 2 \Theta$ and $\mathrm{R}(300) 42.58^{\circ} 2 \Theta$. This operation was performed to all diffraction patterns within martensitic transformation temper- 
ature range. By plotting all the linear functions, their slopes and intercept were compared with temperature. For better understanding of analysis peak intensities are also analysed. It was observed that when B2 phase shifts into $\mathrm{R}$ phase the line changes its slope to values closer to zero. After that when $\mathrm{R} \leftrightarrow \mathrm{B} 19^{\prime}$ transformation starts to occur slope hardly changes while its intercept change rapidly (Fig. A1). To analyse presence of B19' phase well separated (200) peak at $39.15^{\circ} 2 \Theta$ position was taken into account.
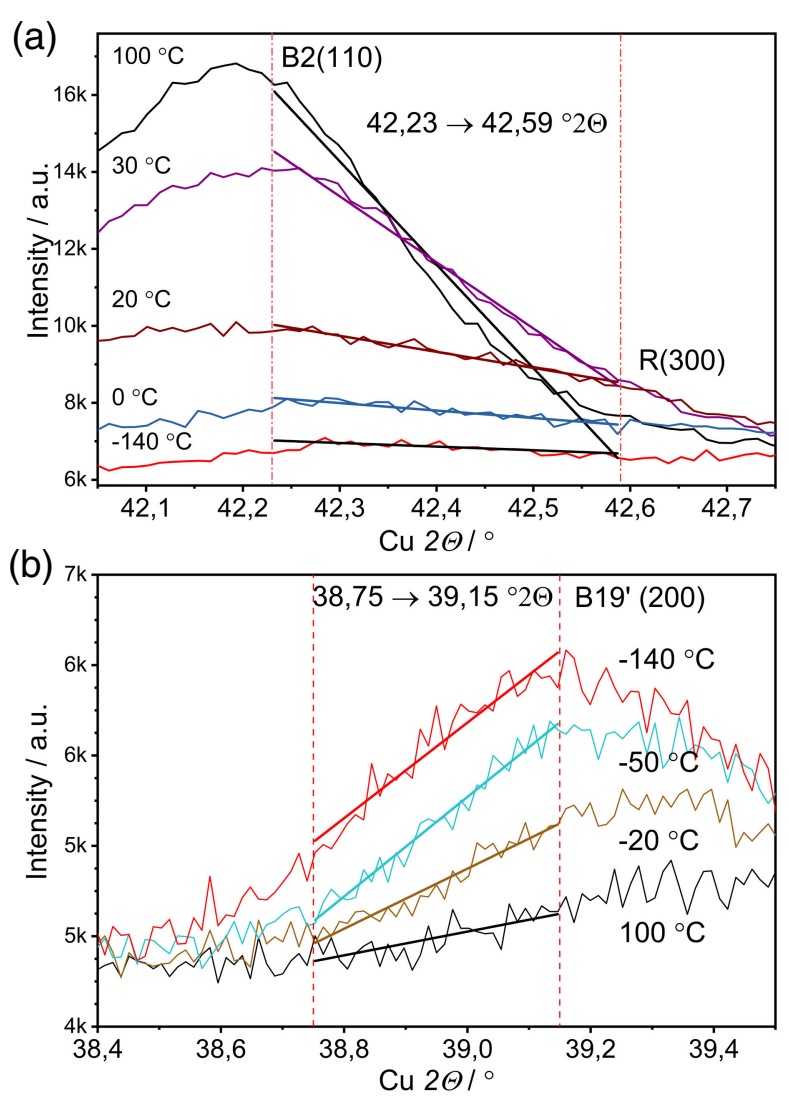

Fig. A1 Graphs showing adopted method to analyse martensitic transformation for (a) B2, R and (b) B19' phases. 